\title{
The Theoretical Foundations of Dispersion of Amplitude-Frequency Characteristics of the Alpha Rhythm of the EEG
}

\author{
Rosman SV* \\ Physician of functional diagnostics of SBIH, Regional psychoneurological clinic, Russia
}

Submission: June 27, 2017; Published: July 05, 2017

*Corresponding author: Rosman SV, Physician of functional diagnostics of SBIH, Regional psychoneurological clinic, Tver, Russian Federation, Russia, Tel: +7-903-800-11-05; Email: seros2005@mail.ru

\section{Abstract}

In view of the new fractal conception of brain activity introduces the theoretical basis of a unique research method - dispersion of amplitudefrequency characteristics of the alpha rhythm, which is a marker of entropy neuron-glial networks of the brain underlying pathogenesis of mental diseases.

\section{Keywords: Fractal model of the brain; The variance of the alpha rhythm EEG; A new method of diagnosis of mental illness}

Abbreviations: DAFCAR: Dispersion of Amplitude-Frequency Characteristics of the Alpha rhythm EEG; NGNB: Neuron-Glial Network of the Alpha Rhythm; CDol: The Dispersion Coefficientalpha-Rhythm-1; Mf 01(O2)-F3(F4): Value of the Difference of Modal Frequencies Between the Occipital and Frontal Electrodes; F3(F4): Values of the Modal Frequencies in Frontal Electrodes; f 01(02): Values of the Modal Frequencies in OccipitalElectrodes; IIDa: Value of the Integral Index of Dispersion (Kurtosis of the Normal Distribution CDal in the Occipital Electrodes; ADA: Value of the Asymmetry CD $\alpha$ in the Occipital Electrodes; IIH: Value of the Index Hypofrontality (Kurtosis of the Normal Distribution CDal) in the Frontal Electrodes; AH: Value of the Asymmetry of CDalin the Frontal Electrodes; c.u.: Conditional Unit

\section{Proceeding}

The main reason that caused the writing of this article, is the deep crisis in which is present the science of studying the brain in General - and psychiatry, and neurophysiology, and addictology, and many other areas of science associated with it. The journal World Psychiatry [1] outlined the problem as the need for new paradigms, the underlying of ideas about how the brain works. In particular, why there are mental illness and what is actually mental illness.

But to get the answer to this question lies one problem despite all the successes of neurophysiology, Cybernetics, and other exact Sciences could not find mates of psychopathology with origin-walking while impaired in NGNB. Moreover, mainly psychiatrists, oddly enough, internally as it has doubts in this respect as the inhabitants of some tribes of Oceania is not aware of the causal connection between sexual intercourse and childbirth. For too long psychiatry has followed a categorical approach to the study of psychopathology, resulting in the introduction of dimensioning methods are often perceived as a blasphemous encroachment on the incomprehensible to the human mind the modalities of the Divine Mind. However, the practical needs of the society sooner or later will force them all to move on to the methods of evidentiary medicine.
It is fair to say that modern neurophysiology offers too little suitable in the practice of the methods of studying the brain in the interests of practical medicine. Some are too complicated and expensive, others inconclusive, others invasive. This limits the access of practitioners to the research that would either confirm or refute the diagnosis of the patient. In order to change the paradigm do not have to destroy everything that exists and start building something completely different from the previous building. Sometimes it is enough to look at the facts from a different perspective, involving, at times, unconventional views and approaches. One such effort was the consideration of the internationally recognized theory of functional systems P. K. Anokhin [2], especially the main part - the theory of afferent synthesis with modern positions. The weak link was the lack of a clear implementation mechanism of afferent synthesis. Get a moose that neurons to perform this function it was necessary to "negotiate" together with power of some unknown mechanism. Such a view throws the researcher back to the idea of the universal Mind, which governs everything, including the work of neurons. Thus we set the task not to solve.

Actually you can do a fairly simple explanation, if you change your views on the interaction of material objects in the 
modern world. The basic idea is the notion that the interaction is an information - either passive (inanimate Nature) or active (wildlife). The main objective of wildlife is opposition to the world of entropy, when implementing a model of "Maxwell's demon", through exchange of substance, energy and information in organisms for which the constituent elements of the objects are connected by controlled feedback, in contrast to inanimate nature, in which the feedback is uncontrollable. The concept of control feedback in the body is fundamental, as it is the quality of the management of these relationships depends on the adequacy of (successful) behavior of the living being in order to survive in the outside world. Evolution of Nature is evolution control feedback loops in the body, which in humans has peaked in the creation of higher nervous activity - thinking.

The material basis of thinking is the NGNB. It is an iterativerecursive system in which glial elements and neuronal components interconnected feedback loops, resulting in the incoming afferent signal, circulating in the network for fur-ISM "re-entry" is the state of neurophysiological irregularity around the neurons according to the type of interference waves on the surface of the water thrown stones at her. As a result, around some neurons are generated electro-physiological conditions for decreasing the threshold of the action potential, and they generate, passing along the axon; around the other neurons, the threshold of the action potential increases, and the neurons remain at rest. Thus, there is a specific neurophysiological configuration that P. K. Anokhin is called the "neural associations". The properties of this neural Association depend on the properties NGNB (cytoarchitectonic in certain conditions, the homeostasis of the organism) and content of the information itself.

Essentially, this is the mechanism of "native encoding" of afferent information, which can be called a fractal modulation mechanism of NGNB, since the iterative-recursive interaction is a principle of creation of fractals by Mandelbrot [3]. The principles of fractal geometry were applied in psychiatry before, but they concern some General processes of mental activity [4]. In the present work the fractal principle is applied to a specific mechanism of functioning of the NGNB $[5,6]$.

The fractal concept of NGNB has 3 main pillars:

a. Fractalmechanism of creation of theelectrophysiological configuration NGNB

b. The mechanism of "fractal scenario"

c. Fractal morphogenesis

Fractal mechanism of creation of the electrophysiological configuration NGNB is the direct mechanism of the reunification of afferent information from the fractal information NGNB configuration and create a new neurophysiological configuration NGNB, resulting in an Association of neurons that produce action potential that is transmitted later in the efferent centers.
These centers form the efferent response. This mechanism is amazing in its simplicity and incredible effectiveness because the information capacity of the Mandelbrot fractal, given its voluminous nature of the brain, boundless, appreciate it makes no sense (Figure 1).

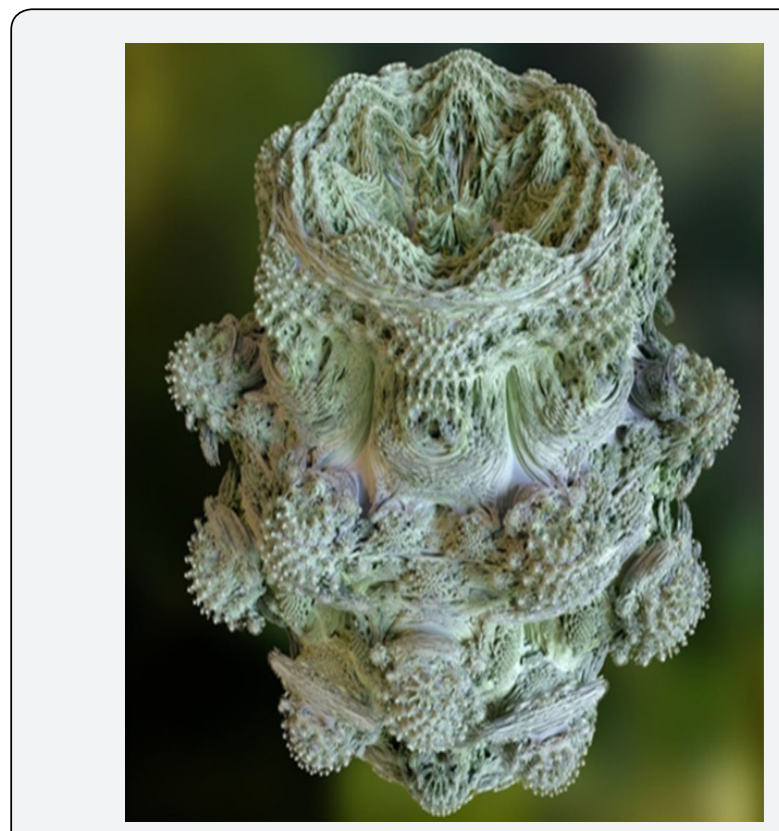

Figure 1: Three-dimensional model of the Mandelbrot fractal the "mandelbulb".

That's why all the afferent information coming into the brain, of the month. One of the most amazing properties of this system is that it does not require the existence of memory in the sense we imagine - in the form of a repository of images or texts, which is necessary for digital technology - in the form of hard drives and SSD. That's why human memory can't find - it "smeared" in a fractal configuration NGNB. The mechanism of functioning of such a system is that the afferent information coming into the brain, alters the structure of the existing neurophysiological NGNB volume of the fractal, creating the new informational reality is that transform even the structure of the NGNB. New fractal "launches" a new neural Association, which indulges in other parts of the brain by neural connections. From there, according to feedback the results of the fractal transformation is returned in the centers of the encoding of afferent information, "correcting" existing there fractal. Because the mechanism of fractal feedback in the brain, which is the basis of creating fractal script efferent response.

Next time the appearance of afferent information that match its configuration with configuration NGNB, runs from fractal scenarios associated with this information, without any search previously seen the image somewhere in memory. Thus, the need for the memory in the image store just yet. All these features of processing of afferent information, among other things, suggests that artificial intelligence will never be able to catch up with the human brain, because it cannot have such plasticity. It is 


\section{Global Journal of Addiction \& Rehabilitation Medicine}

technically impossible to change the structure of chips and links them 10 times per second - at the same frequency produces sampling information in the brain with the goal of creating the time sweep.

This mechanism easily explains the possibility of channeling our activities - because we can simultaneously write, enjoy your favorite music, answer the Intrusive questions of his wife and to think about plans for your holiday weekend. The computer is doing the IRQ interrupt system, which is fundamentally impossible in a biological object because of the incredible (from the standpoint of computer technology) persistence of biological structures. The problem is solved with the help of incredible information capacity of neurophysiological volume of the fractal, which allows you to be more fractal scenarios.

You can add that all of this polymorphic pattern is complicated by the fact that it must exist in the space-time continuum, in other words - we have to accept the information, the time-varying in order to correctly interpret it and to predict its behavior. For this there is the system sample rate information, the predicted 50-ies of the twentieth century Norbert Winner [7]. It was he who, when studying the alpha rhythm of the EEG, compared with the system of vertical sweep of the TV, where the change in afferent information is simulated in the brain by sampling it with a frequency of about $10 \mathrm{~Hz}$ and analysis of the resulting differences. Indeed, by studying the EEG in the 20-ies of XX century it was established that the fluctuations of EEG potentials are harmonic in nature - this phenomenon was called the alpha rhythm.

Later were found and other fluctuations, but they appeared more often in pathological conditions or in the changing mode, "sleep-Wake". Undoubtedly, the oscillatory nature of the activities NGNB spawned many theories, but the most compelling is the idea that the basis of these harmonious changes are selfoscillating reaction Belousov-Zhabotinsky [7], is closely related to the conditions for the maintenance of homeostasis in the body. Sampling data over time in the brain - another of his offspring, we can "extend" or "accelerate" it by changing the operation parameters NGNB. Perhaps outside our consciousness time does not exist, because only the brain to optimize its work, carries on the discretization of the information flow.

The last element of the concept is fractal morphogenesis. Certainly, here we must pay tribute to the outstanding Cybernetics A. Turing [8]. The essence of this mechanism is that transferred to the periphery of efferent information to create neurophysiological fractals in organs and tissues of the body, with the result that it is possible to control their morphological structure and functions. Consideration of this issue is the subject of a separate article [6], but here it is impossible not to point out the following property of the fractal morphogenesis, it eliminates the problem of randomness of gene mutations in Darwin's theory of evolution because it explains management impact directly on the genotype of an organism. In addition, due to the presence of "scrap" DNA. In the course of the project "human Genome" was determined the DNA sequence of all chromosomes and mitochondrial DNA. Currently, these data are widely used worldwide in biomedical research. Full sequencing revealed that the human genome is only $1.5 \%$ of the total genetic material encodes proteins or functional RNA.

The rest is non-coding DNA, often called junk DNA. Actually it is not a genetic reserves or genetic waste production: it is encoded in the structure plan and the sequence of the creation managerial system by the body. That is why in embryogenesis there is a step-by-step transition from the unicellular organism through the intermediate phylogenetic forms to man. If the genotype contained the structure of the organism itself, there would be no need to create intermediate forms. Fractal morphogenesis is a source of concern, but also a messenger of great hope-the possibility of entering human consciousness from the information revolution in an updated form. The exponential ability of our grandchildren to the rapid assimilation of modern digital technology, we believe the result of saturation of its surrounding space. Maybe it's not only this, but in the fact that the genotype of the population began to change in accordance with environmental changes, and brain cytoarchitecture of our descendants become better adapted to the development of information technologies, and we stand at the beginning of this journey.

Unfortunately, the same can be said about the propensity to addictive diseases, drug addiction, alcoholism, gambling for some of these diseases have already become hereditary. You may ask, why I describe all these difficulties. This is done in order to convincingly prove that there are no other objective reasons for the emergence of a variety of mental effects, in addition to the features of the interaction between afferent information and the neurophysiological properties NGNB. These qualities are largely determined by the processes of entropy, which naturally occur in NGNB and in the Universe as a whole. The acceleration of entropy in NGNB for one reason or another and is the morphological substrate of any mental illness. In order to diagnose a mental illness and understand its causes should be found tokens of abuses in NGNB.

With this purpose used a variety of neurophysiological techniques, but, as already indicated, many of them are either scarce or too invasive, or uninformative. Electroencephalography their origin is in the XIX century and during that time have experienced the rapid UPS and bitter disappointment. To date, the General attitude towards her as a nonspecific method of researching functions of the brain, mainly in epyleptology, firmly rooted among the practitioners. Together with the experts of the EEG always intuitively felt that there is a correlation between the rhythm of the oscillations of the potentials of the brain and the severity of mental disorders. This conviction was strengthened with the advent of computer EEG and by detailed 
spectral analysis by the method of Fourier. Here is revealed the amazing properties of the alpha rhythm in the EEG spectrum. It is universally acknowledged that this rhythm is the most important, since only he has shown some very significant patterns associated with brain activity.

a) Alpha rhythm is the only continuously existing (even in a much Decines-ironiziruya EEG) component of the EEG and, most importantly, the permanent component in healthy patients.

b) In the ontogenesis of the alpha rhythm undergoes a natural transformation, and they are connected not with Mosh-ness, and with frequency. The frequency, increasing from 4 years to approximately $1 \mathrm{~Hz} /$ year to 7 years up to 9 $\mathrm{Hz}$, with which, apparently, is associated with the beginning of man's awareness of themselves as individuals and optimal early learning to pubertal period reaches more than 10 $\mathrm{Hz}$ and in the absence of pathogenic causes is kept at this level until approximately 60 years, after which it begins to progressively decline. No other rhythm still does not reveal such strict laws, as a manifestation is usually pathology or a transition to another functional state, for example, in the cycle "sleep-Wake".

c) The frequency of the alpha rhythm correlates with the cognitive abilities of an adult: the higher the frequency, the higher intellectual abilities. The frequency of the alpha rhythm should not be below of $9.75 \mathrm{~Hz}$ as below this frequency it starts an exponential decline in General intelligence, i.e. not separate knowledge and skills, and the ability to adequately digest information and, most importantly, effectively analyze it.

d) Experts have noted repeatedly splitting the spectrum of the alpha rhythm in psychopathology, such as schizophrenia and organic brain disease

All these qualities testify to the close Association of the alpha rhythm with the activity of the NGNB. The intent of research in this area is a test of the main hypothesis - psychopathology is a consequence of disruption of activities NGNB, a marker which is the disorganization of the alpha rhythm is the only rhythm of the EEG exhibiting natural ontogenetic-cal properties. This disorganization is manifested by splitting of the spectrum of the alpha rhythm - a fact, repeatedly celebrated by many researchers. The complexity of the practical application of this phenomenon was the lack of methods for its verification. In the framework of solving this problem has been studied the possibility of identifying a correlation between the degree of splitting of the alpha rhythm and the ratio of the maximum power fluctuations to its total capacity throughout the range of the alpha rhythm (Figure 2A). On a large number of studies have shown that it represents the dispersion coefficient CD $\alpha 1$ is in inversely proportional relationship with the degree of split of the alpha rhythm and the degree of severity of the clinical manifestations of organic brain diseases. Calculating values $\mathrm{CD} \alpha 1$ on the leads and the frequencies we placed the values obtained in the table-the matrix (Figure 2B), which was the basis of the volume distribution plot of the power of the alpha rhythm in head surface (Figure 2C) - this technique is called dispersion mapping of alpha rhythm.

In search of verification of dispersion changes in the alpha rhythm, we proceeded from the hypothesis that the normal distribution of the power fluctuations of EEG potentials in the range of the alpha rhythm in the spectrum is normal. The increase of entropy in the NHS GM with psychopathology leads to a splitting of the spectrum of the alpha rhythm and deviation of this distribution from normal. Thus, markers of the splitting of the alpha rhythm, along with $\mathrm{CD} \alpha 1$ are the parameters of the normal distribution - kurtosis and skewness, which are presented in the analysis of variance index of dispersion. You should only add that in the analysis of variance of the alpha rhythm and this is very important - not investigated the distribution of the power or amplitude of the alpha rhythm and its present value is the fraction of power at a given frequency to the total power fluctuations in the alpha rhythm, which is expressed by the indicator CD $\alpha 1$. In more detail, the method of dispersion mapping and calculation of indexes of dispersion presented in the cited literature [9-11].

What gives us this technique, applied to the stated theme? It was found that DAFCAR quite correctly reflects the degree of impaired mental condition of the person, helps dia to Nesterovich certain forms of psychopathology and to observe the dynamics of the progression of the pathological process. Thus was obtained a possibility not only to visualize the process for qualitative assessment, but also to obtain verified data for conducting correlation and differential diagnostic analysis. Normal distribution $\mathrm{CD} \alpha 1$ в each allocation of frequencies is normal. From a practical point of view, the dispersion map is ordered in nature (Figure 3) and is characterized by certain properties (Table 1).

Dispersion index of alpha-rhythm EEG - dimensional distribution chart, equipotential areas of $\operatorname{CD} \alpha 1$ values with a step of 0.025.ed. An example of such graphs is a physical geographic map, where different colors represent region with the same height above sea level. Cartograms hemispheres are identical and symmetric about the modal value. Sameness and symmetry is an important indicator that indicates that the bulk of cells in both hemispheres works almost in the same mode. It is important to note that fluctuations in the difference of the dispersion indicators are not so significant as variations in the amplitude indicators of the alpha rhythm. This proves that the values are not so dependent on external circumstances, which allows you to compare cartograms of different patients with the standard norms and with those of other patients, the amplitude parameters of the alpha rhythm which is not comparable with our study. 
Table 1: The main parameters DAFCAR normal.

\begin{tabular}{|c|c|c|c|c|c|c|c|}
\hline $\begin{array}{l}\text { Electrodes } \\
\text { EEG }\end{array}$ & $\begin{array}{c}\text { The modal frequency of } \\
\text { the alpha rhythm (Mof), } \\
\mathrm{Hz}\end{array}$ & $\begin{array}{l}\text { The difference is Mo f } \\
\text { in comparison with the } \\
\text { occipital, } \mathrm{Hz}\end{array}$ & $\begin{array}{l}\text { The difference is } \\
\text { Mo f hemispheres } \\
\text { (LH-RH), Hz }\end{array}$ & $\begin{array}{l}\text { CD } \alpha 1 \text {, } \\
\text { c.u. }\end{array}$ & $\begin{array}{c}\text { CDo2 , } \\
\text { c.u. }\end{array}$ & $\begin{array}{l}\text { Kurtosis, } \\
\text { c.u. }\end{array}$ & $\begin{array}{l}\text { Asymmetry, } \\
\text { c.u. }\end{array}$ \\
\hline Fp1-A1 & 10.069 & 0.079 & -0.145 & 0.193 & 0.561 & 5.493 & 2.295 \\
\hline F3-A1 & 10.088 & 0.06 & 0.04 & 0.192 & 0.563 & 5.366 & 2.256 \\
\hline F7-A1 & 10.052 & 0.095 & -0.019 & 0.194 & 0.564 & 5.619 & 2.325 \\
\hline T3-A1 & 10.126 & 0.021 & 0.376 & 0.156 & 0.505 & 3.706 & 1.871 \\
\hline C3-A1 & 10.045 & 0.102 & 0.081 & 0.163 & 0.527 & 4.045 & 1.948 \\
\hline T5-A1 & 10.064 & 0.083 & 0.124 & 0.162 & 0.512 & 3.704 & 1.901 \\
\hline P3-A1 & 10.183 & -0.036 & -0.055 & 0.192 & 0.584 & 4.3 & 2.081 \\
\hline 01-A1 & 10.148 & - & -0.078 & 0.269 & 0.714 & 6.685 & 2.599 \\
\hline Fp2-A2 & 10.214 & 0.012 & - & 0.163 & 0.501 & 3.141 & 1.791 \\
\hline F4-A2 & 10.048 & 0.179 & - & 0.16 & 0.499 & 3.08 & 1.743 \\
\hline F8-A2 & 10.071 & 0.155 & - & 0.151 & 0.487 & 2.653 & 1.668 \\
\hline T4-A2 & 9.75 & 0.476 & - & 0.121 & 0.417 & 1.398 & 1.25 \\
\hline C4-A2 & 9.964 & 0.262 & - & 0.14 & 0.473 & 2.143 & 1.54 \\
\hline T6-A2 & 9.94 & 0.286 & - & 0.182 & 0.555 & 3.282 & 1.86 \\
\hline P4-A2 & 10.238 & -0.012 & - & 0.204 & 0.627 & 4.009 & 2.079 \\
\hline O2-A2 & 10.226 & - & - & 0.28 & 0.729 & 6.582 & 2.553 \\
\hline
\end{tabular}

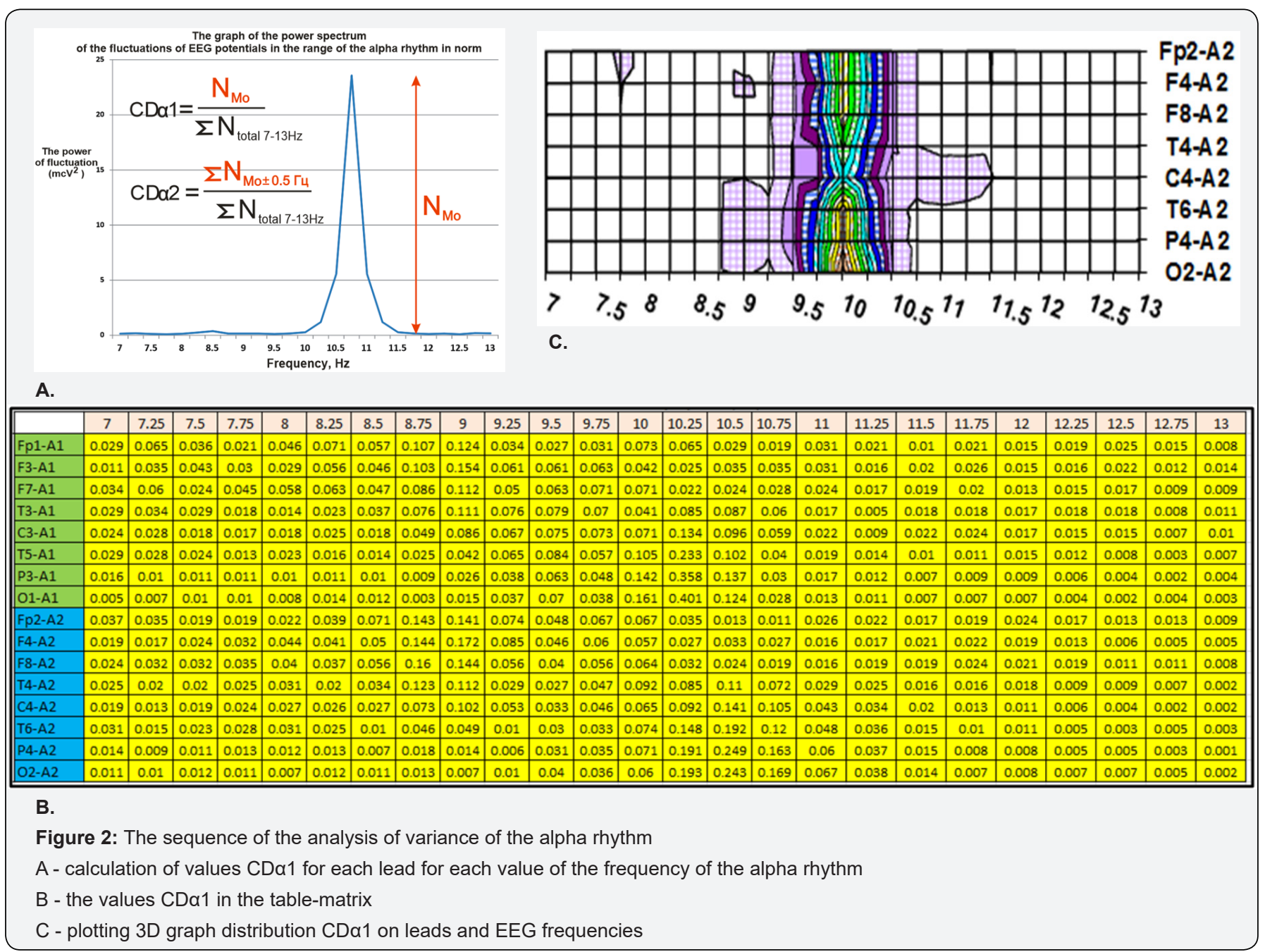


a) On the chart there is a Central modal region $(\mathrm{CD} \alpha 1=$ 0.20-0.25 or more on the scale of the map - area to the right of the green in the box - Figure 3, p. 1)

b) It has expressed in all leads (including frontal) steammodal region of blue color $(\mathrm{CD} \alpha 1=0.15-0.20)$ within \pm 0.25 $\mathrm{Hz}$ of the Central modal value, which may be intermittent introduced in the temporal and Central leads (perhaps, the influence of $\mu$-rhythm) - (Figure 3, p. 2)

c) There pre-modal the blue region of color within \pm 0.5 $\mathrm{Hz}$ of the Central modal values $(\mathrm{CD} \alpha 1=0.10-0.15$ - Figure 3 , p. 3).

d) Peripheral area with a solid violet color, characterized by increased $C D \alpha 2$ - power ratio of alpha rhythm in the range of Mo $\pm 0.75 \mathrm{~Hz}$ to the total power in the range of 7-13 Hz (covering at least $65 \%$ of the power of the alpha rhythm, $\mathrm{CD} \alpha 1=0.05-0.1$ - Figure 3, p.4).

e) Marginal region - in the small purple box. In the Mature brain, the expectation of distribution this area $\pm 1.5 \mathrm{~Hz}$ from the Central modal values (CD $\alpha 1<0.05$ - Figure 3, p. 5).

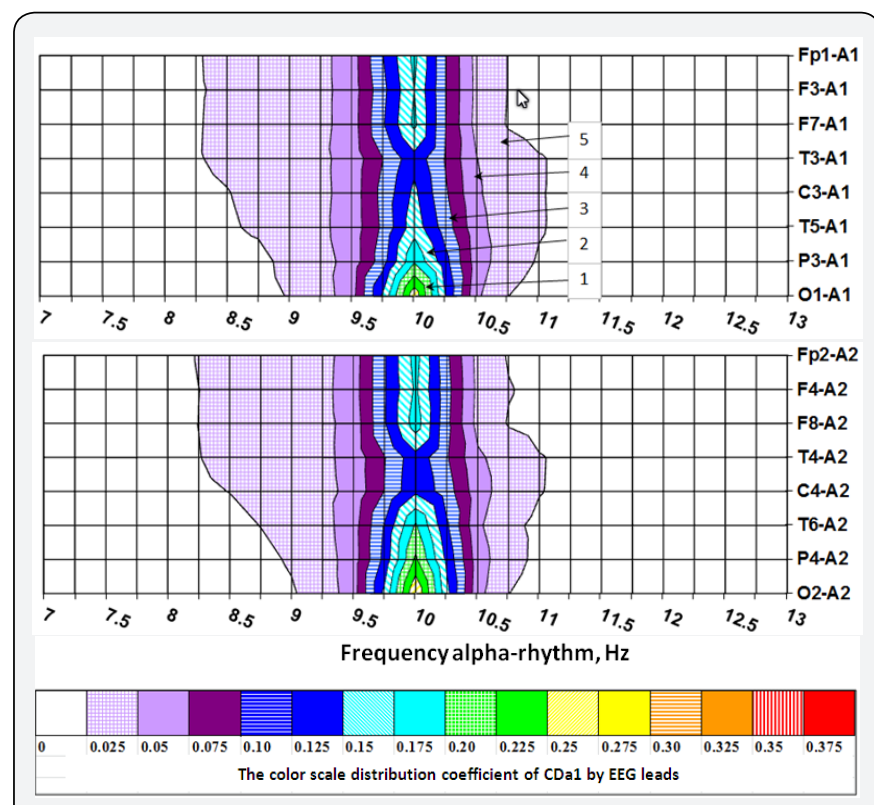

Figure 3: The average dispersion index in normal (top - left hemisphere, bottom - right hemisphere)

f) Modal frequency for each hemisphere and individual leads do not differ by more than $0.25 \mathrm{~Hz}$

g) The share of the low-frequency component of the alpha rhythm -0.2 , medium -0.75 , high frequency is 0.05 .

h) Indicators $C D \alpha 1$ hemispheres differ from each other by no more than 0.05 , and $C D \alpha 2$ not more than 0.1

In addition, to implement the stated purpose of finding deviations of the distribution from normal CD 1 1calculated modal frequency and the dispersion indices. Modal and frequency indices of dispersion indicate the degree of acceleration or deceleration of the alpha rhythm in absolute values and one section of brain relative to another:

a. The modal frequency of the alpha rhythm in the frontal $(F 3, F 4)$ leads - fF3(4) and occipital $(01,02)$ leads - f01(2), $\mathrm{Hz}$

b. The difference between the modal frequency was in the frontal(F3, F4) and occipital(01,02)derivations for each hemisphere of the brain (fO1-fF3 - the left hemisphere fO2$\mathrm{fF} 4$ - the right hemisphere), $\mathrm{Hz}$

c. $\quad \mathrm{Kl}$ - showing the proportion of power of low frequency alpha-rhythm in the gross capacities of all the electrodes of the hemisphere (alpha-1(7-9 Hz)/alpha summary. [\%] - the overall slowing of the alpha rhythm in the hemisphere;

d. $\mathrm{Km}$ - same for mid-frequency alpha-rhythm (alpha 2(9$12 \mathrm{~Hz}$ )/alpha summary. [\%]);

e. Kh- the same for high frequency of the alpha rhythm (alpha-3(12-14 Hz)/alpha summary. [\%]) - indicator of the total acceleration of the alpha rhythm in the hemisphere; Dispersion the index of the alpha rhythm shows degree of deviation of power distribution of the alpha rhythm in the spectrum from normal:

f. IIDA - integral index of dispersion of the alpha rhythm the kurtosis of a normal distribution $C D \alpha 1$ in occipital leads $(01,02)$

g. IIG - integrated index of hypofrontality - the kurtosis of a normal distribution $\mathrm{CD} \alpha 1$ in the frontal leads (F3, F4)

h. ADA - the asymmetry of the dispersion of alpha-rhythm asymmetry of the normal distribution CD 1 in occipital leads $(01,02)$

i. $\quad \mathrm{AH}$ - hypofrontality asymmetry - asymmetry normal distribution $\mathrm{CD} \alpha 1$ in the frontal leads (F3, F4).

It is a recognized fact that EEG is a nonspecific method of research, i.e. no EEG changes (except the epilepsy) can be associated with a clinical change in psychiatry. Despite this we attempted to apply this technique on a large clinical material, referring to one simple fact - in medicine there are many non-specific research, without which the diagnosis may be questioned. For example, erythrocyte sedimentation rate or body temperature. It is not excluded that the dispersive indices of the alpha rhythm, without being specific changes represent an important characteristic of NGNB.

After analyzing all the above we decided to test one of the hypotheses, which is more than 150 years. In German psychiatry in 40-60 - ies of the XIX century there was a view that the allocation of various forms of psychoses (schizophrenia, affective psychoses) probation and unreasonably, that is a single mental disorder, undergoing successive stages in its development: mania, melancholy, insanity and dementia. This idea was 


\section{Global Journal of Addiction \& Rehabilitation Medicine}

expressed by German psychiatrists Neumann, Zeller, and later Griesinger [12]. Griesinger believed the disease is reversible at the stage of affective and affective-delirious disorders, reduction of hallucinatory-delusional disorders and dementia seemed unlikely. Unified theory of psychosis was not conclusively disproved - it simply is not enough material (morphological, morpho-functional) confirmation. What if this succession of phases is based on varying degrees of disorganization NGNB?

Method of standard EEG study with the arrangement of the electrodes according to the international scheme "10-20\%" were examined patients with different psychopathology; the control group consisted of 165 healthy young men who have the Commission of experts found no mental abnormalities. Then, according to the study was created by the dispersion diagrams (Figure 3) and calculated the indices DAFCAR basic mental-for the diseases were ranked by averaged main index - CD $\alpha 1$. These diseases are lined up in sequence; the final link of this chain was a gross violation of Dement (Table 2).

Table 2: The results of the ranking of categories of mental illness (ICD-10) by the values of the primary dispersion coefficient of alpharhythm (CDa1).

\begin{tabular}{|c|c|c|c|c|}
\hline Diagnostic category & $\begin{array}{l}\text { The } \\
\text { number of } \\
\text { cases }\end{array}$ & CD $\alpha 1$ & $\mathrm{CD} \alpha 2$ & IIDA \\
\hline Mentally healthy & 165 & 0.264 & 0.730 & 6.92 \\
\hline $\begin{array}{l}\text { F60. Emotionally unstable } \\
\text { personality disorder }\end{array}$ & 423 & 0.198 & 0.588 & 3.91 \\
\hline $\begin{array}{l}\text { F70.x Mild mental } \\
\text { retardation }\end{array}$ & 446 & 0.189 & 0.569 & 3.67 \\
\hline $\begin{array}{c}\text { F07. Personality and } \\
\text { behavioural disorders due to } \\
\text { brain disease, damage and } \\
\text { dysfunction }\end{array}$ & 138 & 0.181 & 0.552 & 3.37 \\
\hline $\begin{array}{l}\text { F23. Acute and transient } \\
\text { psychotic disorders }\end{array}$ & 65 & 0.173 & 0.5470 & 3.12 \\
\hline F20.x. Schizophrenia... & 617 & 0.161 & 0.523 & 2.65 \\
\hline $\begin{array}{l}\text { F06. Other mental disorders } \\
\text { due to brain damage and } \\
\text { dysfunction and to physical } \\
\text { disease }\end{array}$ & 241 & 0.153 & 0.508 & 2.64 \\
\hline $\begin{array}{l}\text { F71.x. Moderate mental } \\
\text { retardation }\end{array}$ & 45 & 0.150 & 0.529 & 2.43 \\
\hline $\begin{array}{c}\text { F02. Dementia in other } \\
\text { diseases classified elsewhere }\end{array}$ & 303 & 0.148 & 0.522 & 2.19 \\
\hline $\begin{array}{l}\text { F72.x Severe mental } \\
\text { retardation }\end{array}$ & 5 & 0.144 & 0.460 & 2.81 \\
\hline F01. Vasculardementia... & 52 & 0.140 & 0.487 & 1.70 \\
\hline
\end{tabular}

The analysis of these data suggests that the diversity of psychopathology is reduced to gradually increasing dementia, which is pathological entropy NGNB with the growing disorganization of the decline in her functional abilities. A marker of this process is the buildup of DCHAR. Visual reflections of this process in EEG research are deviation of the distribution of the power spectrum of the fluctuations of EEG potentials from normal ("splitting" of the spectrum) and characteristic changes in the dispersion map. Verification it is the reduction of indices DAFCAR. The ability to use digital indexes allows you to create a verified scheme of the progression of dementia in the form of an "axis of dementia" (Figure 4).

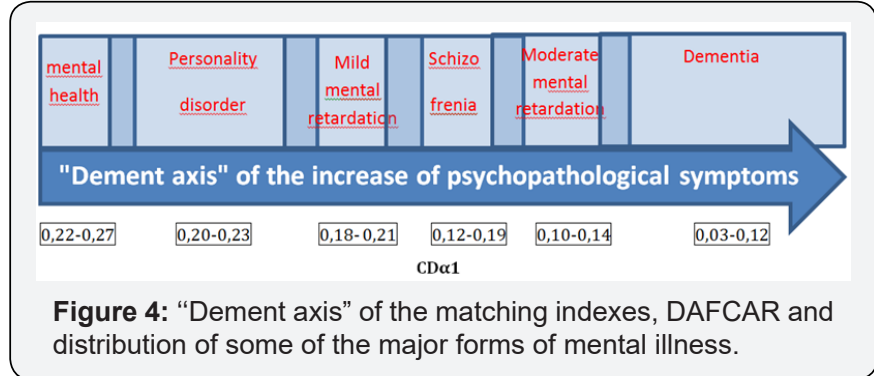

"Axis of Dementia" is a verified model of stages of progression of psychopathological process in connection with the growth of entropy NGNB. In continuation of this work was created by the dispersion models of the major mental illnesses, the enforcement of which is beyond the scope of this article. They show that each model, despite its similarity with the others, has its individual characteristics, allowing to determine the statistical probability of belonging to a specific nosological form. In addition, in the framework of the same pathological process analysis of variance allows to reveal such nuances, which were not available to clinicians. A historical example is the tremendous advancements in the study of cardiac arrhythmias with the invention of the ECG.

The technique of analysis of variance of the alpha rhythm develops, the next step in expanding its capabilities is used in the analysis of the results of hyperventilation samples $[13,14]$. Gets its visual and verified confirmation is widely known in the psychopathology of the phenomenon of hypofrontality [15]. An objective proof was fraught with considerable technical difficulties. Analysis of variance allows verifying the phenomenon of the accelerated dismantlement when alpha rhythm is not slowing down, as if hypofrontality and accelerated, which has its peculiar symptomatology within schizophrenia.

The practical significance of the research, DAFCAR, in the case of independent confirmation of these data, it is difficult to overestimate. Of course, there are other options disorganization NGNB, but they have yet to open and DAFCAR there is already a fairly developed statistical base for a variety of psychopathology. On the principle of analysis of variance of changes in the alpha rhythm created one of the first devices of the series "psychodetector", allowing semi-automatic mode, in the outpatient setting to identify patients with psychopathology (device, Medical Computer Systems, Zelenograd, Rossia) [16]. There are very interesting data for "borderline mental diseases" that allow for the early detection of persons with deviant behavior and a tendency to addictive diseases. On 8 January 1989 near Kegworth (GB) Boeing 737 crashed because the pilot mistakenly shut off the only working engine. Many have puzzled over why the pilot did so. The study, DAFCAR with the 
use of hyperventilation of the sample gives to this question a convincing answer. This and many other cases the scan will find the answer in subsequent articles on the subject [17-19].

\section{Conclusion}

a. Dispersion of amplitude-frequency characteristics of the alpha rhythm - a new informative method of research is neuron-glial network of brain.

b. The method of DAFCAR based on modern fractal concept of functioning NGNB, which allows overcoming the existing difficulties in explaining the diverse phenomena of brain activity.

c. Psychopathology is the result of a disruption of communication from the diseased NGNB, and because of DAFCAR is a marker of these disorders, the use of dispersion mapping, and analysis of variance of the alpha rhythm are reasonable methods in the diagnosis of mental diseases.

d. The wide application of DAFCAR can be an important step in the prevention of psychopathology and identify persons representing a danger to themselves and others and study of the underlying causes of addictive diseases.

\section{References}

1. Sanislow Charles A (2016) Updating the Research Domain Criteria. World Psychiatry 15(3): 222-223.

2. Graham Loren R (1987) Science, Philosophy, and Human Behavior in the Soviet Union, Columbia University Press, UK.

3. Mandelbrot B (1977) The fractal geometry of nature. WH Freeman, New York, USA.

4. Koga, Patrik Marius (2006) A fractal model for psychiatric diagnosis. For: XIV WC of WPA (in press), 2007. 10. Molchanova E. Fractal analysis as one of the Possible Epistemological Approach in Psychiatry and Psychology. Iasi, Romania, 33-38.

5. Rosman SV, Volkov VP (2016) Fractal hypothesis of brain activity and certain aspects of its application. Mental health 4: 72-76.

This work is licensed under Creative Commons Attribution 4.0 License DOI: 10.19080/GJARM.2017.02.555587
6. Rosman SV, Volkov VP (2015) Fractal theory of Central nervous system and morphogenesis of internal organs. Universum: Medicinaifarmakologija: the electronic scientific journal.

7. Wiener N (1948) Cybernetics or Control and Communication in the Animal and the Machine. The Technology Press and John Wiley \& Sons, Inc. - Paris: Hermann etCie, New York, USA.

8. Turing AM (1952) The chemical basis of morphogenesis. Philosophical transactions of the Royal Society of London. Series B Biological sciences 237(641): 37-72.

9. Rosman SV (2013) Diagnostic capabilities of dispersion mapping the alpha rhythm of the electroencephalogram. Mental health 6: 64-69.

10. Rosman SV (2013) Opportunities of the dispersive mapping of the alpha rhythm of electroencephalogram in diagnostics of schizophrenia. Psychiatry 2: 32-37.

11. Rosman SV, Shpak LV (2013) New approaches to the assessment of polymorphism of the alpha rhythm of the electroencephalogram with mental illness. Mental health (2): 39-44.

12. Grisinger W (1845) Pathologie und Therapie der psychischen Krankheiten, Stuttgart.

13. Davis H, Wallace W (1972) Factors affecting changes produced in the electroencephalogram by standardized hyperventilation. Arch Neuropsychol 47: 606.

14. Gibbs FA, Davis H, Lennox WG (1935) The electroencephalogram in epilepsy and in conditions of impaired consciousness. Arch Neurol Psychiatry 34(6): 1133-1148.

15. Goldberg E (1989) A reticulo-frontal disconnection syndrome. Cortex 25(4): 687-695.

16. Maximova NE, Rosman SV, Shpak LV, Zabodaev SV (2016) Possibilities of use of dispersion of an alpha rhythm for screening verification of mental diseases. Mental health 1: 16-25.

17. Gyorgyi L, Turanyi T, RJ Field (1990) Mechanistic Details of the Oscillatory Belousov-Zhabotinskii Reaction. J Phys Chem 94(18): 7162-7170.

18. Marks-Tarlow T (1999) The self as a dynamical system. Nonliner Dynamics, Psychology and Life Sciences 3: 311-345.

19. Field RJ, Richard M Noyes (1974) Oscillations in chemical systems. IV. Limit cycle behavior in a model of a real chemical reaction. J Chem Phys 60: 1877-1884.

\section{Your next submission with Juniper Publishers will reach you the below assets}

- Quality Editorial service

- Swift Peer Review

- Reprints availability

- E-prints Service

- Manuscript Podcast for convenient understanding

- Global attainment for your research

- Manuscript accessibility in different formats ( Pdf, E-pub, Full Text, Audio)

- Unceasing customer service

Track the below URL for one-step submission https://juniperpublishers.com/online-submission.php 